\title{
OS TERMOS NEOLATINOS PARA A DESIGNAÇÃO DA "BONECA"
}

Para Teresa Cristina.

Maria Luisa Fernandes Miazzi

A palavra "boneca" foi das mais comuns por longo tempo em casa, pois era uma constante no vocabulário de minhas filhas, introduzindo-se de modo espantoso mesmo na fala dos adultos

"Nenê qué muneca", "dá muneca mim" são expressões de que me recordo freqüentemente e que me faziam naqueles anos distantes imaginar por que razão as meninas substituíam a oclusiva labial pela nasal homorgânica. Influência da avó espanhola que só aparecia uma vez por semana? Não o creio, embora talvez o infalível casaquinho ou roupinha que ela trazia "para la muñequita" pudesse ter deixado conseqüências lingüísticas.

Mais tarde, deparando com o termo galego moneca, pensei na antiga dúvida. Também a labial (oclusiva ou nasal, surda ou sonora) aparecia em outras línguas românicas: fr. poupée, it. bambola, ret. poppa, sardo puppu, rom. papusa, etc. Haveria uma raiz comum?

Pelo menos deveria existir uma na Ibéria, contendo como segundo elemento consonântico a nasal dental geminada, uma vez que permanecia em nossa língua e se palatalizava no castelhano. E qual a relação com o resto da România? Ainda mais, perguntava-me, o esp. muñeca teria alguma afinidade com o adjetivo mona que significa "graciosa"? E óbvio que eu só tinha em mente nossas lindas bonecas atuais ao dizer: "Que mona es la muñequita!" E mona com o sentido de "macaca" poderia ter igual étimo? Além disso, o esp. muñeca, na acepção de "munheca", seria na origem a mesma palavra que também se traduzia por "boneca"? E qual a razão da nasal dental no cat. nina?

Essas perguntas e outras reuni, depois, e investiguei a procedência dos termos que me foi dado coligir: a maioria deles provém do 
lat. pupa, diretamente ou por sufixação, mas a Ibéria mostra um tipo especial, certamente com base na linguagem infantil, que é a responsável pelo do italiano, do romeno, e, afinal, mesmo do latino.

\section{1 - EM LATIM}

a) Em latim o termo próprio para designar a "boneca" é pupa; havia, além de pupa (ou puppa), o seu diminutivo pupula, aplicado à "menina" e também à "pupila" (menina dos olhos).

Pupa (puppa) origina-se da linguagem infantil (a forma geminada é semelhante à que parece eem acca, atta, pappa), segundo Ernout e Meillet (1). Sobre as formas femininas pupa, puppa, pupula, surgiram as correspondentes masculinas, pupus, puppus, pupulus, porém de uso raro e que mal sobreviveram (2).

Ainda sobre pupula formou-se um segundo diminutivo, pupilla, que deu origem, na língua do direito, ao sentido de "pupila, órfã" Como pupula, pupilla também designa a "menina do olho", assim chamada por causa da imagenzinha que nele se vê refletida.

Esses três sentidos básicos encontram-se no gr. кó p "menina; boneca menina do olho"

Uma quarta acepção tomou o vocábulo puppa na linguagem infantil (não aparece no latim literário), pois se reencontra nas línguas neolatinas: o de "seio materno", "teta" (3).

Vejamos a documentação dessas formas latinas, extraída primacialmente de Forcellini (4).

PUPA (ou PUPPA) - Tem duas acepçōes: "menina" e "boneca"

1) Corresponde a puella e ao gr. кóp plo de Marcial (4, 20): "Dicit se vetulam, quum sit Caerellia pupa, Pupam se dicit Gellia, quum sit anus." (Cerélia, embora seja moça, se diz velhinha; Gélia diz-se mocinha, embora seja velha).

2) Por extensão, passou a designar a "boneca", em geral feita com enchimentos vários e revestidos de linho, a qual se cobria de roupas e servia de brinquedo para as meninas; na puberdade, era ofere-

(1) - Dictionnaire Etymologique de la Langue Latine, s.v.

(2) - Pupulus "boneco de cera" aparece em Arnóbio, cf. Torrinha, Dicionário Português-Latino. mamar.

(3). - Ainda hoje se ouve a criança exprimir por "pupu" o desejo de

(4) - Lexicon Totius Latinitatis, tomo III, s.v.

Agradeço à Profa. Neyde Ramos de Assis a colaboração na pesquisa deste material. 
cida a Vênus como símbolo de sua virgindade para que lhe fosse concedido um casamento feliz. Testemunha Varrão (apud Nônio, 156, 20. Merc.): "Magna pars in desiderium puparum et sigillorum veniebat." (Uma grande parte vinha em busca de bonecas e estatuetas).

PUPULA - E o diminutivo de pupa, que também significa "menina" (puella) e ainda a "pupila" (dos olhos).

1) No sentido próprio surge bem documentado numa inscrição (apud Gruter, 627, 9, que a extrai de Orell. 3031, cf. Forcellini, s.v.,):

\section{A PVPVLA ANNIS VIGINTI OBTINVI DOMVM OMNEM.}

Também neste sentido exprime conotação afetiva, de carinho. Ex.: "Sed adhuc istud, mea pupula, ministrare debebis. Hic Venus loquitur ironice ad Psychen" (Mas ainda, minha menina, deverás servir. Aqui Vênus fala ironicamente a Psiquê.) (Apul. 6. Met.)

2) Com a acepção de "menina dos olhos" aparece claramente em Cícero (2.Nat. D.57, 142): "Palpebrae aptissime factae et ad claudendas pupulas, et ad aperiendas." (As pálpebras feitas com muita propriedade não só para fechar as pupilas mas também para abrir).

PUPILLA - E um segundo diminutivo formado sobre pupula (ou seja, equivalente a puellula, parva pupa), com o sufixo -illa; designa a moça órfã de pais, que vive sob tutela, e ainda a pupila dos olhos (e até o próprio olho).

1) No sentido de "moça que tem um tutor", surge em Cícero (3, Verr 58, 153): "Iste infanti pupillae fortunas patrias ademit." (Esse tirou à pupila infante os bens paternos.)

2) Quanto ao sentido de "menina dos olhos", lemos em Cícero (2, Nat. D. 57, 142): "Acies ipsa, qua cernimus, quae pupilla vocatur, ita parva est, ut. " (A própria menina do olho, com a qual vemos, a qual se chama pupila, de tal forma é pequena que. .).

Por extensão, o próprio olho recebe tal designação em Apuleio (3, Met.): "Defrictis adeo diu pupillis, an vigilarem scire quaerebam. " (Desse modo, esfregados os olhos por muito tempo, eu procurava saber se ficaria acordado.)

b) Em latim vulgar, ocorre também o vocábulo pupa com o sentido de "moça, menina" Assim temos em inscrições de Pompéia (5): 31 tu, pupa, sic valeas, / sic habeas / Venere Pompeianam / propytia // munn./

(5). - M. Diaz y Diaz, Antologia del Latin Vulgar, p. 30 e 32. 
510. pupa que bela is, tibi / me misit qui tuus es: val (e).

\section{2 - NAS LINGUAS ROMÂNICAS}

Sobrevivência dos termos latinos ocorre não só na maior parte das línguas, já mencionadas, como também em formas dialetais, consoante revela o exame de atlas linguísticos (em especial o ALF e o AIS). Pupa manteve-se de um modo geral, especialmente no galoromance e ítalo-romance, com o sentido latino de "menina" e "boneca", e ainda na acepção posterior de "teta, mama" Não subsistiram vestígios de pupula, mas o segundo diminutivo, pupilla, permaneceu no italiano e, através da medicina, foi emprestado pelo francês e demais línguas.

$\mathrm{Na}$ Ibéria, no italiano e no romeno temos formações novas para designar a "boneca", todas extraídas da linguagem infantil.

NO IBERO-ROMANCE: port. boneca, gal. moneca (6), esp. muñeca, cat. nina

Nos idiomas peninsulares não vingou o lat. pupa. já no Glosario del Escorial (1400), ele é traduzido por munneca.

E teoria aceita (7) que os vocábulos da Ibéria teriam surgido de formas afetivas latinas, da linguagem infantil, ninna, nonna. MeyerLübke (REW 5817) acrescenta ainda nanna à série, donde a nossa expressão "fazer nana"; de ninna retira ele o it. ant. ninna "mellina", esp. niña, port. nene, assim como de nonna, o it. nonna "avó", fr. nonne "freira, nutriz" Aliás, numa inscrição do baixo latim ocorre MONNA, como termo de carinho usada pelo marido para com a esposa; é de certo a palavra nonna com dissimulação consonântica, embora Ernout e Meillet perguntem se haveria ligação com o gr. $\mu o ́ v a ~(8)$.

O étimo ninnus, $-a$ é confirmado por Corominas para o esp. niño, $-a$, assim como também para o cat. nin, $-a$; associa ainda a forma nino da Madeira, apesar de que em galego-português tenha do-

(6). - Não aparece nos dicionários galegos, diz Corominas (DCELC), mas temo-la, por ex., no título de um poema de Vigo J.M. Posada: "A moneca"

(7) . - Ver J.P. Machado (DELP e Corominas (DCELC)

(8). - No verbete nonnus, - $a$, Ernout e Meillet afirmam a origem

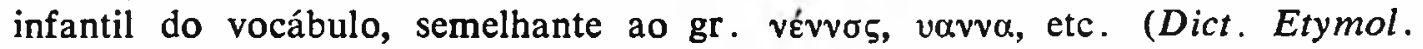
Langue Latine). 
minado o termo menino (9), o qual, por ser de criação afetiva, tem origens similares.

A ninna associa J.P.Machado o beirão nena "boneca de pano" e, de nonna, com dissimilação, extrai monna que dá o esp. moña, a que se uniria o sufixo -eca para formar "muñeca" Para o galego a explicação também satisfaria e, no caso do português, teria havido nova dissimilação de nasais .

E preferível essa teoria, segundo parece, à anteriormente usada entre os autores, que associavam a palavra "boneca" aos adjetivos bom e bonito ou a um deles. Para A. Coelho quiçá "boneco" fosse o nome dado a uma figura do teatro de bonifrates (10); e João Ribeiro tentou relação do port. boneca, esp. muñeca com mona "bruxa", a partir de mona "macaca" Em verdade, mono significa no espanhol "boneco, títere", além de "macaco", enquanto o adjetivo mono equivale a "bonito, gracioso, engraçado" Todavia, embora o gasção mounaco "figurinha informe" pudesse aduzir novo testemunho, não podemos aceitar mona "símio" como étimo, pois, além de não explicar a nasal palatal espanhola, é palavra de origem tardia (11).

Prefere Corominas (DCELC) buscar a origem da palavra $m u$ ñeca "boneca" numa extensão de muñeca "munheca", "articulação da mão com o braço" (também "alvo", "fito" e ainda "embrulho de trapo de forma arredondada"). Em espanhol antigo era moñeca, oriundo de moño com seu sentido etimológico de "objeto avultado" (12); inicialmente se pensaria numa "protuberância nessa articulação" e, depois, o vocábulo passaria a designar a mesma articulação.

A forma monnieca aparece nos Libros del Saber de Astronomia de Alfonso el Sabio para indicar a articulação da mão e braço; em Nebrija aparece muñeca no sentido dessa parte do braço, mas logo se preferiu especificar: "la muñeca del braço" (Glos. del Escorial e Toledo).

(9). - A procedência da palavra portuguesa menino tem sido muito discutida. Quise am extraí-la do esp mi niño, mas Corominas contesta, devido à sua antigüidade na língua (atestada desde 1254); é preferível deriva-la da linguagem afetiva, como é o caso do fr.ant. mignot "lindo", cat. minyó "rapaz, menino", it . mignolo "o dedo mínimo" homem".

(10). - Bonifrate, originalmente "bom irmão", indicaria apenas "bom

(11). - A origem de mono, - a "símio" é incerta; sugere uma abreviação de mamona, variante de maimon, - ona, do á:abe maimûn "feliz" (pois, ao que parece, os macacos procediam da Árabia Feliz ou Yemen); cf. da mesma raiz, o ingl. monkey.

(12) . - Moño deve provir de uma raiz pré-romana munn -, cujo sentido seria o de "protuberância, objeto volumoso, e que deixou vestígios também nos dialetos vascos. 
E quanto ao sentido da mesma palavra espanhola para designar a boneca? Já no Glosario del Escorial temos a expressão "muñeca de trapo"; e Alonso de Palencia (13) menciona "las muñecas que fazen las niñas" Depois, também surge a palavra na acepção de "embrutho de trapo arredondado com que se embebem líquidos", etc.

Mas o sentido mais antigo com que aparece o vocábulo no espanhol é o de "marco divisório"; a primeira documentação, "illa Monneka", datando de 1011, aparece em Castilla la Vieja; num documento de Santana, datado de 1210, aparece "la tierra de Vellida que est so la monneka"

Ainda segundo Corominas, outro sentido, muito restrito, o de "espantalho", surge em catalão dialetal - monaca - e se usa apenas em Vallespir, cf. o ALC, mapa 188.

Uma hipótese, lançada por Thurneysen e aceita por MeyerLübke (REW 5747), foi a de que muñeca "munheca" e "boneca" teria ligação com um tipo *mundiare "limpar" > "podar", "cortar", derivado de mundus "limpo" Todavia, hoje se refuta, à vista das relações inegáveis entre a raiz já referida de moño (munn-, com a variante munni-), a que se prende o fr. moignon "resto de membro mutilado", hoje "resto de ramo cortado", o cat. monyo, também "resto de membro mutilado", e a raiz bunn-, bunni- que teria originado o cat. bony, gasc. bougno e fr. ant. e dial. bugne, todos com o sentido de "vulto, volume" A aproximação dessas raízes é evidente no jud. esp. buñeca ou muñeca, que se usa indiferentemente na Bulgária com a nasal ou a labial.

\section{NO GALO-ROMANCE}

O vocábulo francês para "boneca", poupée, vem do lat. puppa com sufixo e é atestado desde o séc. XIII, J. de Meung (14). Aliás, no galo-romance não subsistiram vestígios da forma simples latina (em contraposição ao ítalo-romance), tanto nos dialetos franceses como provençais (15). No provençal antigo temos popada e, nos modernos dialetos, persiste a composição: poupeyo, pipado, poupôio, etc.

Com o sentido de "bebê", criancinha nova" aparece no fr. arc. poupellon, no fr. med. poupette, poupin etc. e no fr. mod. pou-

(13). - No Universal Vocabulario en latin y en romance, Sevilla, 1490, sempre segundo Corominas (DCELC).

(14). - Bloch \& Wartburg, Dict. Etym. Langue Française, s.v. (FEW) .

(15) - W v Wartburg, Französisches Etymologisches Wörterbuch 
pelin; hoje também poupard (designa igualmente a "boneca"), o diminutivo poupon, etc.

Para indicar a "mulherzinha" e a "boneca", o fr. ant. tinha popine (daí o adjetivo do fr. med. popin, mod. poupin "belo, pequeno, enfeitado."

$\mathrm{Na}$ acepção de "seio, teta" surge no ant. prov. popa, popeta, e ainda no fr. med. poupe "mama de animais ferozes", fr. mod. poupelin, "mama"

\section{NO ITALO-ROMANCE}

Bambola é o termo do italiano-padrão, enquanto dialetalmente subsistem derivados do lat. pupa.

a) Bambola é o vocábulo generalizado para designar a "boneca" Bem a definem Rigutini e Fanfani (16): "figurina fatta di cenci o d'altro vestita da donna, e che si dà a' bambini per trastullo." O diminutivo bambolina é comum, aplicando-se mesmo a jovens: "bambina o giovane che pare una bambola"

Segundo Zingarelli (17), só cabe à "giovane donna con viso bello ma inespressivo" o termo bambola, embora o aceite como neologismo para a "giovane donna vistosamente bella"; a conotação "senza espressione alcuna" para a menina de rostı) branco e vermelho "che pare una bambola" também é feita por Rigutini e Fanfani. Perde-se depois para indicar simplesmente a "donna simile a bambola" (18).

A origem de BAMBOLA estaria numa raiz expressiva bamb, donde o ital. ant . bambo, que mediante sufixo diminutivo deu o moderno bumbino. Na Introdução (19), Meyer-Lübke, referindo-se a formações onomatopaicas, inclui o caso específico de bimbo "menino" ao lado de bambino, assim como bambo "infantil", bambino, bambolo, bamboccio "menino, boneca", que teriam apôio no lat. bambalo "ga-

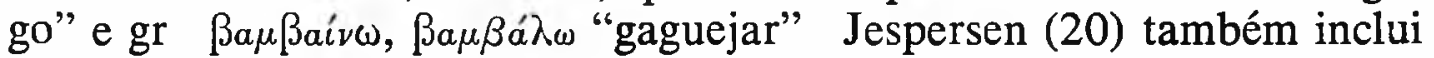
o termo bambo (bambino) e os nomes para a "boneca" lat. pupa ou puppa, al. Puppe, ingl. puppet) entre os devidos à linguagem infantil .

(16). - Vocabolario Italiano della Lingua Parlata, s.v

(17). - Vocabolario della Lingua Italiana, s.v.

(18). - Spinelli e Casasanta, Dizionario Completo Italiano-Portoghese

(Brasiliano) e Portoghese (Brasiliano) - Italiano.

(19) - Introdução ao Estudo da Glotologia Românica, p. 149-150.

(20). - Language, p. 157 
Uma peculiaridade semântica surge na expressão "avere la bambola" usada para indicar o ciclista extenuado por muito esforço.

Ainda em italiano se pode exprimir, por meio de pupa e o diminutivo pupattola, tanto a menina como a boneca, de acordo com o étimo latino; e, dialetalmente, temos a sua continuação em abundância, como em geral no ital. set. pupa, lomb. pua, piem. büata (com sufixo), sic. e cal. puppa, etc.

Também em dialetos limítrofes temos a sobrevivência da palavra latina, no sentido de "criança": frl. pup, istr. pupo.

Mesmo na acepção de "pupila" pode ocorrer preservação do vocábulo simples: abruzz. puppa de l'okkye .

Quanto ao sentido posterior de "teta, mama", temo-lo no it . poppa, donde o $\mathrm{v}$ poppare "mamar" e certos derivados: poppina "maminha" (no ant. it . poppina significou também "olho")

Nota:

No SARDO houve a mencionada sobrevivência da forma masculina puppu e ainda a de pupa como "pupila": log. pupa s'oyu (FEW, vb. pupa, e REW 6.854). Também log. pubada "boneca" (FEW).

RETICO (21) - No engadino encontramos poppa que admite dois sentidos: o de "bebê, criança de leite" e o de "boneca" Também se aplica ao "globo ocular" - poppa del ögl — e aparece na expressão poppa d'üert, que designa o "espantalho" (22).

\section{NO BALCANO-ROMANCE}

a) Para o DALMÁTICO, só encontramos atestado, na parte do léxico veglioto de Das Dalmatische (23), o termo popaile, designativo das "pálpebras": le popaile dei vakli "as meninas dos olhos"

Lembre-se que a palavra usual para indicar "menina, jovem" é no veglioto de origem eslava: trok, troka (troc, troci, troce). Muito corrente nos textos (24), é bem possível que também se haja aplicado para indicar a boneca, embora não consignado tal sentido.

(21). - Incluímos aqui o rético no ítalo-romance - como até fizemos com o sardo - devido à aproximação dos étimos, sem cogitar de ítalo ou reto-romance ou língua de transição.

(22) - Baseamo-nos no Diczionariu scurznieu de la lingua ladina, de A. Velleman, publicado pela Engandin Press Co.

(23).- M. Bartoli, Das Dalmatische, vol. II, col. 45, 44.

(24). - Figuram em abundância na coletânea de fls. 5-35 em nossa tese, ainda inédita, intitulada $O$ dialeto veglioto. 
b) No ROMENO temos o vocábulo papusa, que procede igualmente de um da linguagem infantil, pappa "pai" (25), e apresenta sentido tríplice, segundo Damé (26):

1) o de boneca ou marionete (ex.: gatita ca o papusa "vestida como uma boneca");

2) o de pelota (ex.: papusa de sfoara "pelota de barbante");

3) o de folhas que revestem a espiga de milho (ex.: papusa de tutun "rolo de tabaco para mascar")

\section{CONCLUSÃO}

Em latim o vocábulo pupa (puppa e até puppa), proveniente da linguagem infantil, que significava "menina, moça", passou também a designar a "boneca" e sobreviveu, especialmente com o último sentido, nas línguas românicas, através da forma simples no ítalo-romance como no rético e sardo, e com sufixos no galo-romance.

O seu diminutivo pupula não persistiu na România, mas sim um segundo, formado sobre ele, pupilla, na acepção de "menina dos olhos" (ex.: vegl . popaile) e como termo jurídico que indica a "moça tutelada"

De pupa, que em inscrições vulgares ainda se apresenta como "jovem", surgiu posteriormente, devido ao linguajar das crianças, o sentido de "mama, teta", que entrou ocasionalmente em alguns idiomas (it. poppa, fr. med. poupe).

Outros vocábulos, igualmente da linguagem infantil, deram origem às formas do ibero-romance, do italiano-padrão e do romeno. Nas línguas da Ibéria, a base dominante é uma raiz munn- que aparece nos vocábulos do espanhol e do galego-português; quanto ao catalão, também se fundamenta num tema expressivo, ninna. No italiano, a raiz bamb) aparece em termos afetivos, tanto no que exprime "criança" (bambino,-a) como no designativo de "boneca" (bambola). Enfim no romeno, também de palavra da linguagem infantil, pappa "pai", surgiu a raiz de papusa "boneca""

Fica, pois, evidente o caráter afetivo de todos os vocábulos que indicam a "boneca" no latim e línguas românicas, surgidos como meios

(25). - O étimo é dado por Puscariu, apud REW 6213). Originalmente - sentido de pappa estaria relacionado com a comida (ainda hoje port. "papa", "papinha"), mas adquiriu alhures, mo:mente no grego, o sentido de "pai", que foi recebido pelo latim: pappas ou papa, - atis (cf. Ernout e Meillet, Dict. Etym.).

(26). - Frédéric Damé, Nouveau Dictionnaire Roumain-Français, $3^{\circ}$ vol. 
de expressão da criança; e, em geral, existe relação entre o vocábulo para "menina" e para "boneca"

Podemos terminar com a série de nomes aplicados à "boneca" nas línguas e principais dialetos neolatinos:

port. boneca, gal. moneca, esp. muñeca, cat. ninna; fr. poupée, prov arc. pupada, prov dial. poupeyo, poupôio, pipado, pupado, etc. fr.-cond. pupé; it. bambola (dial.: set. pupa, sic. cal. puppa, etc); ret. (eng.) poppa; (log.) pubada; rom. papusa.

\section{BIBLIOGRAFIA}

BARTOLI, M. - Das Dalmatische (Altromanische Sprachreste von Veglia bis Ragusa und ihre Stellung in der Appenninobalkanischen Romania), Kaiserliche Akademie de: Wissenschaften, Viena, 1906.

BLOCH, O \& WARTBURG, W - Dictionnaire étymologique de la langue française. 2a ed., Paris, PUF, 1950.

COROMINAS, J. - Diccionario Crítico Etimológico de la Lengua Castellana. Madrid, Edit. Gredon, (1954) 4 v.

DAMÉ, F — Nouveau Dictionnaire Roumain-Français. Bucarest, Imprimerie de l'Etat, 1894, $4 \mathrm{v}$.

DIAZ y DIAZ, M. - Antologia del Latin Vulgar. Madrid, Edit. Gredos, (1950).

ERNOUT, A. MEILLET, A. - Dictionnaire Étymologique de la Langue Latine. $3^{\circ}$ ed., Paris. C. Klincksieck, 1951.

FORCELlINI, Aeg. - Lexicon Totius Latinitatis. Patauii, Typis Seminarii, 1940 , t. III .

JESPERSEN, O. - Language, London, George Allen \& Unwin Ltd. (1a. ed. 1922), 10 ed. 1954.

MACHADO, J.P - Dicionário Etimológico da Língua Portuguesa. [Lisboa] Confluência, 1952-1959. $2 \mathrm{v}$.

MEYER-LÜBKE, W. - Introdução ao Estudo da Glotologia Românica. Red. port. de A. Júdice, Lisboa, Livr. Class. Edit., 1916.

Romanisches Etymologisches Wörterbuch. Heidelberg, Carl Winters Universitätsbuchandlung, 1935.

NASCENTES, A. - Dicionário Etimológico da Língua Portuguesa, Rio, Fr. Alves-Machado, 1932.

RIGUTINI e FANFANI - Vocabolario Italiano della Lingua Parlata, Firenze, G. Barbera, Edit., 1854.

SPINELLI, V \& CASASANTA, M. - Dizionario Completo Italiano-Portoghese (Brasiliano) e Portoghese (Brasiliano) - Italiano. Milano, U. Hoepli, $19572 \mathrm{v}$ 
TORRINHA, F - Dicionário Português-Latino. $2^{\circ}$ ed., Porto, Domingos Barreira, 1939.

Dicionário Latino-Português. 3. ed., Porto, Maranus, 1945.

VELLEMAN, Diczionariu scurznieu de la lingua ladina, Engandin Press Co.. Samaden, 1929.

WARTBURG, W. - Französisches Etymologisches Wörterbuch. Basel, R.G. Zbinden \& Co., 1959, Lief. nr. 68/69, p. 601-608.

ZINGARELLI, N. - Vocabolario della Lingua Italiana, Bologna, Zanichelli Ed., 1963. 